ASTHMA

\title{
Do farming exposures cause or prevent asthma? Results from a study of adult Norwegian farmers
}

\author{
W Eduard, J Douwes, E Omenaas, D Heederik
}

Thorax 2004;59:381-386. doi: 10.1136/thx.2004.013326

See end of article for authors' affiliations ....................

Correspondence to: Dr W Eduard, National Institute of Occupational Health, P O Box 8149 Dep, 0033 Oslo, Norway; wijnand.eduard@stami.no

Received 18 July 2003 Accepted 26 January 2004

\begin{abstract}
Background: A protective effect of endotoxin exposure on atopy and asthma in farmers' children has been postulated. Studies of adult farmers have shown conflicting results but often lack exposure data. The prevalence of asthma in farmers with different exposure levels to microbial agents and irritant gases was compared.

Methods: Atopy was defined as a positive response to multiple radioallergosorbent tests (RAST) with a panel of 10 common respiratory allergens, and asthma was ascertained by a questionnaire using a stratified sample $(n=2169)$ of a farming population from south-eastern Norway. Exposure of farmers to total dust, fungal spores, bacteria, endotoxins, and ammonia was assessed by exposure measurements. Results: The prevalence of asthma was $3.7 \%$ for physician diagnosed asthma and $2.7 \%$ for current asthma. The prevalence of atopy was $14 \%$, but most asthmatic subjects were non-atopic (80\%). Compared with farmers without livestock, (1) asthma was significantly higher in cattle farmers $\left(\mathrm{OR}_{\text {adj }} 1.8,95 \% \mathrm{Cl} 1.1\right.$ to 2.8$)$ and pig farmers $\left(\mathrm{OR}_{\mathrm{adj}} 1.6,95 \% \mathrm{Cl} 1.0\right.$ to 2.5$)$, (2) non-atopic asthma was significantly higher in pig farmers $\left(\mathrm{OR}_{\mathrm{adj}} 2.0,95 \% \mathrm{Cl} 1.2\right.$ to 3.3$)$ and in farmers with two or more types of livestock $\left(\mathrm{OR}_{\mathrm{adj}} 1.9\right.$, $95 \% \mathrm{Cl} 1.1$ to 3.3), and (3) atopic asthma was less common in farmers with two or more types of livestock $\left(\mathrm{OR}_{\text {adj }} 0.32,95 \% \mathrm{Cl} 0.11\right.$ to 0.97$)$. Exposure to endotoxins, fungal spores, and ammonia was positively associated with non-atopic asthma and negatively associated with atopic asthma. No associations were found with atopy.

Conclusions: Exposure to endotoxins and fungal spores appears to have a protective effect on atopic asthma but may induce non-atopic asthma in farmers.
\end{abstract}

$\mathrm{R}$ ecent publications have drawn attention to the possibility that growing up on a farm may have a protective effect against the development of atopy and asthma in children, adolescents, and young adults. ${ }^{1-6}$ Contact with livestock seemed to reduce the risk, $^{2}{ }^{4}$ and it has been speculated that respiratory exposure to endotoxin may play an important role ${ }^{57}$ since keeping animals is associated with high exposures to bacterial endotoxins. A recent study in children living in rural areas showed a significant inverse association between indoor endotoxin levels and the occurrence of hay fever, atopic asthma, and sensitisation. ${ }^{8}$ However, other bioaerosol components such as fungal spores, bacteria, storage mites, and other allergens have not been widely studied and may also be important.

An important question is whether the protective effect from exposure to farm animals observed in farmers' children also occurs or persists into adulthood. Studies of farmers and farmer students have reported lower or no excess risk of asthma or atopy. ${ }^{9-12}$ In contrast, other studies have shown substantially increased risks of atopy and respiratory morbidity and mortality including asthma among adult farmers and farm workers. ${ }^{13-17}$ The evidence of a reduced risk of atopy and asthma in adult farmers is therefore unclear.

In order to gain more insight into the role of endotoxins and other microbial agents in asthma and atopy in adult farmers, we compared the prevalence of these outcomes in farmers with different types of production and evaluated their exposure by measurements during farm work.

\section{METHODS}

\section{Farming population}

The farms were located in coastal, inland, and mountainous regions. Participants were selected from the Norwegian government's Register of Farmers. Farmers from three counties in south-east Norway and spouses engaged in farming (all called farmers hereafter) were enrolled ( $\mathrm{n}=10792$ subjects). Of these, 8482 farmers participated in medical examinations during the winter of 1991 including spirometric testing, collection of blood samples, and completion of a questionnaire (participation rate $79 \%$ ). ${ }^{18}$ Based on information from the questionnaire and spirometric tests, hierarchical stratified samples of the participants were selected to reduce the number of subjects for atopy testing. These were all subjects with lifetime self-reported asthma $(\mathrm{n}=524)$ as well as random samples of exclusive categories of participants with ( 1 ) chronic bronchitis ( $\mathrm{n}=198$, sampling fraction 36\%), (2) airway obstruction $\left(\mathrm{FEV}_{1} / \mathrm{FVC}<0.7\right.$, $\mathrm{n}=299,56 \%$ ), (3) work related irritation symptoms of the eyes and airways $(n=322,32 \%)$, and (4) subjects without any of these symptoms $(\mathrm{n}=910,16 \%)$, amounting to a total of 2253. Farmers with incomplete data on smoking $(n=65)$, farm work $(n=296)$, and exposure $(n=317)$, and those who had changed production for health reasons $(n=61)$ or retired from farm work were excluded. Because of overlapping categories, 1614 subjects were available for statistical analyses. The mean (SD) age of the farmers was 46 (10) years and $67 \%$ were male; $47 \%$ had never smoked, $22 \%$ were former smokers, and $31 \%$ were current smokers (adjusted for the stratified sampling).

\section{Questionnaires}

The participants answered a questionnaire on asthma, work participation and duration, and smoking habits. The asthma questions were: "Have you had asthma in the past or now?" with follow up questions: "If yes, do you have asthma now?" (current asthma) and "Was asthma diagnosed by a physician?" (physician diagnosed asthma). The farmers also answered questions concerning asthma in their parents and 
siblings. Questions on smoking habits classified farmers as never, former and current smokers. ${ }^{19}$

Specific tasks carried out by the farmers were recorded by questionnaire including questions on participation in threshing, other grain handling, harvest and handling of silage, hay and straw, sorting potatoes, tending of cattle, swine, poultry, sheep and goats, and handling of dry and liquid manure. Duration of farm work was assessed by questions on part time/full time farming and number of years as a farmer. The subgroup of farmers which participated in the exposure study also answered a questionnaire on numbers of hours spent per year on the tasks recorded in the main questionnaire and specific work operations within those tasks.

\section{Serum IgE}

Blood samples were collected in Vacutainer SST tubes and coagulated at room temperature $\left(18-24^{\circ} \mathrm{C}\right)$ for at least 1 hour before centrifugation. The serum samples were frozen and stored below $-18^{\circ} \mathrm{C}$ before analysis. Samples were analysed for IgE by multiple radioallergosorbent tests (RAST) with the respiratory allergens cat, dog, horse, birch, timothy, mugworth, Dermatophagoides farinae, Cladosporium, Olea europea, Parietaria judaica under standardised conditions (Phadebas Phadiatop; Pharmacia Diagnostics, Uppsala, Sweden). The results were expressed as positive or negative.

\section{Exposure assessment}

An exposure study was nested in the survey of the farming population as described previously. ${ }^{20}{ }^{21}$ In short, personal exposures to total dust, fungal spores, bacteria, endotoxins, and ammonia were measured in a random sample of farms when farmers performed one of 12 specific tasks. These tasks were assumed to include most of the farmers' exposure to bioaerosols. For each of these tasks and each agent we collected 20-30 exposure measurements resulting in a total of 288 sampling sessions. This number of measurements is sufficient to detect a significant difference between two tasks if exposure levels differ by a factor of 4 , with a common geometric standard deviation (GSD) of $4-8$, a significance level of 0.05 , and a power of $80 \%$. More than one task was monitored on a farm if possible, resulting in measurements being carried out on 127 farms. The duration of the exposure study was 5 years in order to include different growing seasons.

For each sampling session two total dust samples were collected simultaneously on $25 \mathrm{~mm}$ diameter polycarbonate filters with pore size $0.4 \mu \mathrm{m}$ (Poretics, Osmonics, Livermore, CA, USA) in conductive standard aerosol cassettes (Gelman, Ann Arbor, MI, USA). One sample was analysed for particle mass by gravimetry and for endotoxins by a Limulus amoebocyte lysate assay. ${ }^{22}$ The other sample was analysed for fungal spores by scanning electron microscopy ${ }^{23}$ and for bacteria by fluorescence microscopy. ${ }^{24}$ Ammonia was measured with indicator tubes (Drägerwerk Aktiengesellschaft, Lübeck, Germany). Ammonia during harvesting and handling of crops was assumed to be negligible in the absence of obvious sources and odour. Yearly average exposures were computed for each agent and farmer as the sum of the time weighted (arithmetic) mean exposure of each task, multiplied by the (arithmetic) mean duration (hours per year) of the corresponding task and divided by a work year of 1800 hours. The farmers were divided into farm production groups depending on the animals tended (cattle, swine, poultry, sheep and goats).

\section{Data analysis}

A positive RAST result was used as the criterion for atopy, and asthma was defined as current asthma or asthma diagnosed by a physician. Subjects with asthma were divided into atopic and non-atopic groups.

Prevalence rates in the farming population were computed using the reciprocal sampling fractions as weights. Exposure data within the farm production groups were approximately $\log$ normally distributed; $t$ tests allowing for unequal variances were used on $\log$ transformed data to test for differences between the groups because the GSD could be different. Correlations between dichotomous and ordinal variables were studied by Goodman-Kruskal tau and Spearman's rank correlation coefficients (rho), respectively. Logistic regression analysis was used to compare the prevalence of asthma and atopy in farmers with different types of production and farming history. Age and seniority as a farmer were categorised in quartiles. Atopy was first treated as a confounder in models of asthma; the population was subsequently stratified by atopic status in models of atopic and non-atopic asthma to evaluate atopy as an effect modifier. The model fit was assessed by the HosmerLemeshow test. The correlation between age and seniority was 0.66 (Spearman's rho). The annual average exposure levels were categorised in tertiles. These variables were moderately to strongly correlated with Spearman's rho values ranging from 0.59 to 0.85 . Other correlations between explanatory variables were low (Goodman-Kruskal tau $<0.05$, Spearman's rho $\leqslant 0.2$ ).

Statistical analyses were performed using EGRET 2.01 (Cytel Inc, Cambridge, MA, USA) and SPSS 9.0 for Windows (SPSS Inc, Chicago, IL, USA).

\section{RESULTS}

\section{Asthma and atopy}

The prevalence of asthma ever diagnosed by a physician was $3.7 \%$ and the prevalence of current asthma was $2.7 \%$. Atopy was found in $14 \%$ of the farmers, but only $20 \%$ of those with current asthma were atopic.

\section{Work exposure in the farming population}

Farmers had worked on the farm for a mean (SD) of 23 (12) years. Full time farming was reported by $64 \%$ and $77 \%$ worked with livestock. Tending of cattle was reported by $51 \%$, swine by $23 \%$, sheep and goats by $21 \%$, and poultry by $11 \%$. Annual average exposure levels are summarised in table 1. Overall, farmers with animal production had a higher exposure to all agents, especially those keeping more than one type of livestock. The exposure patterns depended on type of livestock; poultry farmers had the highest exposure to bacteria, cattle farmers to ammonia, and swine farmers to fungal spores and endotoxins. Full time farmers had a slightly higher exposure to all agents than part time farmers. Only minor differences were found between men and women (results not shown).

\section{Associations between asthma and atopy and work exposure}

The prevalence of current asthma was higher in farmers with livestock than without, especially in farmers keeping more than one type of livestock. Atopy was associated with current asthma (odds ratio (OR) 1.7, 95\% CI 1.1 to 2.7) when included in this model, but the fit was poor $(p<0.01$, Hosmer-Lemeshow test). The model of current asthma had a much better fit when atopy was omitted and the ORs of the other variables showed only small changes. The latter model is therefore used in table 2 which shows that the prevalence of atopy was slightly but not significantly lower in farmers with livestock. Stratification of the population by the presence of atopy revealed clearly different associations. Asthma was almost twice as prevalent in non-atopic farmers with more than one type of livestock than in non-atopic 
Table 1 Annual average exposure to dust, organic dust components, and ammonia in the farming population $(n=1614)$ stratified by type of farm production

\begin{tabular}{|c|c|c|c|c|c|c|c|c|c|c|}
\hline \multirow[b]{4}{*}{ Agent } & \multicolumn{10}{|c|}{ Exposure level† } \\
\hline & \multicolumn{3}{|l|}{ All } & \multicolumn{7}{|c|}{ Livestock tendingł } \\
\hline & \multirow[b]{2}{*}{ GM } & \multirow[b]{2}{*}{ GSD } & \multirow[b]{2}{*}{ Median } & \multirow[b]{2}{*}{ No } & \multicolumn{2}{|l|}{ Any } & \multirow[b]{2}{*}{ Poultry 9} & \multirow[b]{2}{*}{ Sheep/goats बा } & \multirow[b]{2}{*}{ Cattleq } & \multirow[b]{2}{*}{ Swine ब } \\
\hline & & & & & 1 type & $\geqslant 2$ types & & & & \\
\hline Total dust $\left(\mathrm{mg} / \mathrm{m}^{3}\right)$ & 1.6 & 2.9 & 2.2 & 0.32 & 2.0 & 3.7 & 2.4 & 1.1 & 2.1 & 2.5 \\
\hline Fungal spores $\left(10^{6} / \mathrm{m}^{3}\right)$ & 2.0 & 3.9 & 2.6 & 0.35 & 2.5 & 4.7 & 0.7 & 2.2 & $2.8^{*}$ & $3.4^{*}$ \\
\hline Bacteria $\left(10^{6} / \mathrm{m}^{3}\right)$ & 9.2 & 3.7 & 11 & 1.6 & 12 & 23 & 66 & 6.1 & 11 & 16 \\
\hline Endotoxins $\left(10^{3} \mathrm{EU} / \mathrm{m}^{3}\right)$ & 28 & 4.3 & 47 & 3.4 & 39 & 77 & 6.0 & 26 & 46 & 74 \\
\hline Ammonia (ppm) & 3.8 & 5.6 & 7.9 & $0 \S$ & 6.6 & 15 & 2.9 & 5.3 & 10 & 4.2 \\
\hline
\end{tabular}

$G M=$ geometric mean; $G S D=$ geometric standard deviation.

†Geometric mean if not otherwise stated

$\ddagger$ Comparisons between groups by $t$ test for unequal variance. All comparisons were significant at $p<0.001$ except ${ }^{*} p<0.05$.

$\S$ Not measured, set to 0 because sources of ammonia were lacking.

- Exposure levels of farmers tending one type of livestock.

farmers without livestock ( $\mathrm{OR}_{\mathrm{adj}} 1.8,95 \% \mathrm{CI} 1.1$ to 3.2$)$, but it was three times less prevalent in atopic farmers with more than one type of livestock than in atopic farmers without livestock $\left(\mathrm{OR}_{\mathrm{adj}} 0.32,95 \% \mathrm{CI} 0.11\right.$ to 0.97 ; table 2$)$. In the latter and other models with atopic asthma as outcome all non-significant variables were omitted to improve precision as the number of cases was relatively low $(n=33)$.

Models including production type as an exposure variable showed that the prevalence of asthma was significantly higher in cattle farmers $\left(\mathrm{OR}_{\mathrm{adj}} 1.8,95 \%\right.$ CI 1.1 to 2.8$)$ and swine farmers $\left(\mathrm{OR}_{\mathrm{adj}} 1.6,95 \% \mathrm{CI} 1.0\right.$ to 2.5$)$, while atopy did not show any significant associations with production type. Non-atopic asthma was more prevalent among livestock farmers except poultry farmers, and was significantly raised in pig farmers $\left(\mathrm{OR}_{\mathrm{adj}} 2.0,95 \%\right.$ CI 1.2 to 3.3). Livestock farmers (except poultry farmers) had less atopic asthma, but the decrease was not significant for any type of farm production (table 3 ). These findings suggest that asthma could be associated with exposure since the exposure levels of all agents depended on type of farm production (table 1).

This was confirmed in analyses using annual average exposure levels. Models with one agent showed significant positive associations in a dose dependent way between nonatopic asthma and fungal spores, endotoxins, and ammonia (table 3). The same agents were negatively associated with atopic asthma, also in a dose dependent manner, with atopic

Table 2 Associations of asthma and atopy with individual and farm related factors in a farming population $(n=1614)$. Associations with asthma are also shown for atopic $(n=264)$ and non-atopic $(n=1350)$ individuals separately

\begin{tabular}{|c|c|c|c|c|}
\hline \multirow[b]{2}{*}{ Factor } & \multicolumn{4}{|c|}{$\mathrm{OR}_{\mathrm{adj}}$ of risk factor* $(95 \% \mathrm{Cl})$} \\
\hline & $\begin{array}{l}\text { Asthma } \\
(n=164)\end{array}$ & $\begin{array}{l}\text { Atopy } \\
(n=264)\end{array}$ & $\begin{array}{l}\text { Asthma in atopic } \\
\text { farmers }+(n=33)\end{array}$ & $\begin{array}{l}\text { Asthma in non-atopic } \\
\text { farmers }(n=131)\end{array}$ \\
\hline \multicolumn{5}{|l|}{ Age (years) } \\
\hline $1-39$ & 1 & 1 & 1 & 1 \\
\hline $40-46$ & $1.1(0.52$ to 2.2$)$ & $0.82(0.56$ to 1.2$)$ & $0.70(0.20$ to 2.4$)$ & $1.5(0.59$ to 3.6$)$ \\
\hline $47-54$ & $2.3(1.2$ to 4.4$)$ & $0.67(0.44$ to 1.0$)$ & $1.7(0.62$ to 4.8$)$ & $3.2(1.4$ to 7.1$)$ \\
\hline $55-69$ & $5.2(2.6$ to 11$)$ & $0.73(0.43$ to 1.2$)$ & $2.9(1.1$ to 7.8$)$ & $8.2(3.4$ to 20$)$ \\
\hline \multicolumn{5}{|l|}{ Sex } \\
\hline Male & 1 & 1 & & 1 \\
\hline Female & $0.82(0.54$ to 1.3$)$ & $0.81(0.58$ to 1.1$)$ & - & $0.89(0.56$ to 1.4$)$ \\
\hline \multicolumn{5}{|l|}{ Smoking } \\
\hline Never & 1 & 1 & & 1 \\
\hline Former & $1.2(0.74$ to 1.8$)$ & $0.57(0.39$ to 0.85$)$ & - & $1.0(0.64$ to 1.7$)$ \\
\hline Current & $1.0(0.70$ to 1.6$)$ & $0.61(0.45$ to 0.83$)$ & & $1.2(0.74$ to 1.8$)$ \\
\hline \multicolumn{5}{|l|}{ Asthma in family } \\
\hline No & 1 & 1 & 1 & 1 \\
\hline Yes & 2.4 (1.7 to 3.5$)$ & $1.3(0.91$ to 1.7$)$ & 2.9 (1.3 to 6.2$)$ & 2.4 (1.6 to 3.5$)$ \\
\hline \multicolumn{5}{|l|}{ Years of farm work } \\
\hline $0-13$ & 1 & 1 & & 1 \\
\hline $14-20$ & $1.4(0.80$ to 2.6$)$ & $0.87(0.61$ to 1.2$)$ & & $1.9(0.90$ to 3.9$)$ \\
\hline $21-31$ & $1.0(0.53$ to 1.9$)$ & $0.73(0.49$ to 1.1$)$ & - & $1.1(0.52$ to 2.5$)$ \\
\hline $32-64$ & $1.3(0.67$ to 2.7$)$ & $0.39(0.21$ to 0.71$)$ & & $1.5(0.67$ to 3.5$)$ \\
\hline \multicolumn{5}{|l|}{ Farm work } \\
\hline Part time & 1 & 1 & & 1 \\
\hline Full time & $0.78(0.54$ to 1.1$)$ & $1.0(0.74$ to 1.3$)$ & - & 0.75 (0.49 to 1.1$)$ \\
\hline \multicolumn{5}{|l|}{ Farm production } \\
\hline Crop & 1 & 1 & 1 & 1 \\
\hline Livestock (1 type) & 1.1 (0.68 to 1.7$)$ & $0.81(0.57$ to 1.2$)$ & $0.75(0.32$ to 1.8$)$ & 1.2 (0.73 to 2.2$)$ \\
\hline Livestock ( $\geqslant 2$ types) & $1.4(0.84$ to 2.2$)$ & $0.91(0.62$ to 1.3$)$ & $0.32(0.11$ to 0.97$)$ & $1.9(1.1$ to 3.3$)$ \\
\hline
\end{tabular}

*Adjusted by logistic regression.

†Only significant potential confounders were included in this model. 
Table 3 Associations between asthma and atopy and annual average exposure levels in a farming population $(n=1614)$

\begin{tabular}{|c|c|c|c|c|}
\hline \multirow[b]{2}{*}{ Factor } & \multicolumn{4}{|l|}{$\mathrm{OR}_{\mathrm{adj}}$ of risk factor* } \\
\hline & $\begin{array}{l}\text { Asthma } \\
(n=164)\end{array}$ & $\begin{array}{l}\text { Atopy } \\
(n=264)\end{array}$ & $\begin{array}{l}\text { Asthma in atopic farmers } t \\
(\mathbf{n}=33)\end{array}$ & $\begin{array}{l}\text { Asthma in non-atopic farmers } \\
(\mathrm{n}=131)\end{array}$ \\
\hline \multicolumn{5}{|l|}{ Farm production } \\
\hline Crop & 1 & 1 & 1 & 1 \\
\hline Poultry & $1.2(0.64$ to 2.3$)$ & 1.3 (0.72 to 2.2$)$ & $1.2(0.37$ to 4.0$)$ & $0.90(0.43$ to 1.9$)$ \\
\hline Sheep/goats & $1.1(0.52$ to 2.5$)$ & $1.0(0.47$ to 2.1$)$ & $0.59(0.23$ to 1.5$)$ & $1.6(0.69$ to 3.9$)$ \\
\hline Cattle & $1.8(1.1$ to 2.8$)$ & $1.2(0.80$ to 1.8$)$ & $0.58(0.27$ to 1.3$)$ & $1.5(0.88$ to 2.6$)$ \\
\hline Swine & $1.6(1.0$ to 2.5$)$ & 0.84 (0.54 to 1.3$)$ & $0.54(0.19$ to 1.6$)$ & 2.0 (1.2 to 3.3$)$ \\
\hline \multicolumn{5}{|c|}{ Total dust $\left(\mathrm{mg} / \mathrm{m}^{3}\right)$} \\
\hline $0-1.8$ & 1 & 1 & 1 & 1 \\
\hline $1.9-2.6$ & $0.88(0.57$ to 1.4$)$ & $0.98(0.70$ to 1.4$)$ & $0.84(0.36$ to 2.0$)$ & $0.89(0.53$ to 1.5$)$ \\
\hline $2.7-8.0$ & $1.2(0.82$ to 1.9$)$ & $0.89(0.63$ to 1.3$)$ & $0.38(0.13$ to 1.1$)$ & $1.6(1.0$ to 2.6$)$ \\
\hline \multicolumn{5}{|c|}{ Fungal spores $\left(10^{6} / \mathrm{m}^{3}\right)$} \\
\hline $0-1.6$ & 1 & 1 & 1 & 1 \\
\hline $1.7-3.4$ & $1.3(0.82$ to 1.9$)$ & $0.98(0.70$ to 1.4$)$ & $0.55(0.23$ to 1.3$)$ & $1.6(0.96$ to 2.6$)$ \\
\hline $3.5-38$ & $1.2(0.77$ to 1.8$)$ & $0.99(0.70$ to 1.4$)$ & $0.28(0.10$ to 0.78$)$ & 1.7 (1.0 to 2.7$)$ \\
\hline \multicolumn{5}{|c|}{ Bacteria $\left(10^{6} / \mathrm{m}^{3}\right)$} \\
\hline $0-9.1$ & 1 & 1 & 1 & 1 \\
\hline $9.2-14$ & $0.92(0.60$ to 1.4$)$ & 0.91 (0.65 to 1.3 ) & $0.63(0.26$ to 1.5$)$ & 1.0 (0.62 to 1.7$)$ \\
\hline $15-94$ & $1.2(0.78$ to 1.8$)$ & $0.74(0.52$ to 1.0$)$ & $0.54(0.20$ to 1.4$)$ & $1.5(0.93$ to 2.3$)$ \\
\hline \multicolumn{5}{|c|}{ Endotoxins $\left(10^{3} \mathrm{EU} / \mathrm{m}^{3}\right)$} \\
\hline $0-26$ & 1 & 1 & 1 & 1 \\
\hline $27-60$ & $0.97(0.62$ to 1.5$)$ & $1.1(0.76$ to 1.5$)$ & $0.55(0.23$ to 1.3$)$ & $1.1(0.67$ to 1.9$)$ \\
\hline $61-140$ & $1.2(0.78$ to 1.8$)$ & $0.82(0.58$ to 1.2$)$ & $0.34(0.12$ to 0.95$)$ & $1.6(0.99$ to 2.5$)$ \\
\hline \multicolumn{5}{|l|}{ Ammonia (ppm) } \\
\hline $0-4.2$ & 1 & 1 & 1 & 1 \\
\hline $4.3-10$ & $1.2(0.81$ to 1.9$)$ & $0.93(0.67$ to 1.3$)$ & $0.87(0.38$ to 2.0$)$ & $1.4(0.84$ to 2.2$)$ \\
\hline $11-23$ & $1.3(0.87$ to 2.1$)$ & $0.92(0.65$ to 1.3$)$ & $0.31(0.10$ to 0.95$)$ & $1.8(1.1$ to 3.0$)$ \\
\hline $\begin{array}{l}\text { Results of a moc } \\
(n=1350) \text { indiv } \\
\text { *Adiusted by lo } \\
\text { †Only significan }\end{array}$ & ction and single & $\begin{array}{l}\text { odels are shown. } \\
\text { ders were similar } t\end{array}$ & $\begin{array}{l}\text { ns with asthma are also shov } \\
\text { (not shown). }\end{array}$ & - atopic $(n=264)$ and non-atopic \\
\hline
\end{tabular}

asthma being three times less prevalent among farmers exposed to the highest levels. None of the agents was significantly associated with asthma or atopy independently.
Models with two exposure variables indicated that exposure to fungal spores was more strongly associated with atopic asthma than endotoxins and ammonia. The

\begin{tabular}{|c|c|c|}
\hline \multirow[b]{2}{*}{ Factor } & \multicolumn{2}{|l|}{$\mathrm{OR}_{\mathrm{adi}}$ of risk factor* } \\
\hline & $\begin{array}{l}\text { Asthma in atopic farmers } \\
(n=33)\end{array}$ & $\begin{array}{l}\text { Asthma in non-atopic farmers } \\
(n=131)\end{array}$ \\
\hline \multicolumn{3}{|c|}{ Fungal spores $\left(10^{6} / \mathrm{m}^{3}\right)$} \\
\hline $0-1.6$ & 1 & 1 \\
\hline $1.7-3.4$ & 0.51 (0.09 to 3.0$)$ & $2.3(1.1$ to 4.6$)$ \\
\hline $3.5-38$ & $0.31(0.06$ to 1.7$)$ & $1.7(0.81$ to 3.6$)$ \\
\hline \multicolumn{3}{|c|}{ Endotoxins $\left(10^{3} \mathrm{EU} / \mathrm{m}^{3}\right)$} \\
\hline $0-26$ & 1 & 1 \\
\hline $27-60$ & $1.1(0.18$ to 6.6$)$ & $0.59(0.28$ to 1.3$)$ \\
\hline $61-140$ & $0.81(0.15$ to 4.2$)$ & $1.1(0.52$ to 2.2$)$ \\
\hline \multicolumn{3}{|c|}{ Fungal spores $\left(10^{6} / \mathrm{m}^{3}\right)$} \\
\hline $0-1.6$ & 1 & 1 \\
\hline $1.7-3.4$ & 0.31 (0.07 to 1.4 ) & $1.3(0.64$ to 2.8$)$ \\
\hline $3.5-38$ & 0.23 (0.05 to 1.2$)$ & $1.3(0.62$ to 2.6$)$ \\
\hline \multicolumn{3}{|c|}{ Ammonia (ppm) } \\
\hline $0-4.2$ & 1 & 1 \\
\hline $4.3-10$ & $2.2(0.54$ to 9.3$)$ & $1.1(0.56$ to 2.3$)$ \\
\hline $11-23$ & $1.1(0.18$ to 6.2$)$ & $1.5(0.69$ to 3.1$)$ \\
\hline \multicolumn{3}{|c|}{ Endotoxins $\left(10^{3} \mathrm{EU} / \mathrm{m}^{3}\right)$} \\
\hline $0-26$ & 1 & 1 \\
\hline $27-60$ & $0.56(0.16$ to 2.0$)$ & $0.77(0.40$ to 1.5$)$ \\
\hline $61-140$ & $0.48(0.13$ to 1.8$)$ & $1.1(0.61$ to 2.0$)$ \\
\hline \multicolumn{3}{|c|}{ Ammonia (ppm) } \\
\hline $0-4.2$ & 1 & 1 \\
\hline $4.3-10$ & $1.3(0.39$ to 4.1$)$ & $1.6(0.87$ to 2.8$)$ \\
\hline $11-23$ & $0.55(0.12$ to 2.4$)$ & $1.9(0.98$ to 3.6$)$ \\
\hline \multicolumn{3}{|c|}{$\begin{array}{l}\text { Results of models with two exposure variables are shown. The ORs of potential confounders were similar to table } 2 \\
\text { (not shown). } \\
\text { *Adjusted by logistic regression. } \\
\text { †Only significant potential confounders were included in this model. }\end{array}$} \\
\hline
\end{tabular}


association between non-atopic asthma and exposure to fungal spores and ammonia was similar (table 4).

\section{DISCUSSION}

Current asthma was most often found in cattle and swine farmers. Non-atopic asthma constituted more than three quarters of all current asthma in farmers and was more often found among livestock farmers, especially pig farmers. Nonatopic asthma was positively associated with exposure to endotoxins, fungal spores, and ammonia. The same exposures were negatively associated with atopic asthma, and atopic asthma was also less prevalent in livestock farmers.

The participation rate was high $(79 \%)$, limiting the potential for non-response bias. Exposure misclassification was limited by excluding from the analyses farmers who had retired or had changed production because of health reasons. These farmers had more asthma than the selected population ( $9 \%$ and $17 \%$, respectively). Furthermore, $7 \%$ of the retired farmers had retired because of asthma (results not shown). These rates suggest that the prevalence of asthma is underestimated. Farms in Norway are commonly inherited by the first born child. Anecdotal information from farmers indicates that asthmatic children are less likely to take over the farm, which may explain a lower prevalence of asthma in the farming population. The prevalence of asthma increased with age, however, and more than $80 \%$ of the asthmatic farmers were older than 45 years. Self-selection of asthmatic subjects from the population is therefore likely to have a limited effect on the prevalence of asthma in farmers.

The exposure to each agent was estimated from task specific information combining average exposure duration and level. The precision of the exposure data is expected to be higher than usually observed for full shift measurements. However, for both the estimated time and exposure level, the major source of error in this type of study consists of deviations from average values, because average values have been used to describe exposure duration and level for each individual. It is known that individuals may have exposures that are considerably higher or lower than the average observed, and the same is true for the time spent on certain activities..$^{25} 26$

However, this type of error (referred to as Berkson type of error) is usually associated with a considerable loss of power (because differences in exposure exist within exposure categories that are related to the response), but leads to unbiased estimates of the relationship between exposure and effect, apart from an unusual situation with regard to variability in exposure and duration of exposure. ${ }^{27}$

Possible misclassification of exposure among symptomatic farmers (highly exposed tasks were no longer carried out due to respiratory problems) may bias associations between exposure and asthmatic outcomes. If this was the case in the present study, positive effects on non-atopic asthma would have been underestimated and negative effects on atopic asthma overestimated. However, the options for farmers to avoid highly exposed tasks other than quitting or changing production type (which were adjusted for in the analyses) are limited. Furthermore, the positive association with non-atopic asthma was in the expected direction and of the same magnitude as that reported previously in occupational populations. ${ }^{28}$

In children, asthma has almost universally been regarded as an atopic disease involving allergic (IgE mediated) sensitisation with a Th2 CD4+ lymphocyte response and subsequent interleukin-5 mediated eosinophilic airways inflammation, enhanced bronchial reactivity, and reversible airflow obstruction. Although intrinsic asthma in adults is well recognised, atopic mechanisms are still commonly assumed to play a dominant role in adult asthma as well.
Interestingly, we observed that most of the subjects with asthma were non-atopic, suggesting that the role of atopy in the development of asthma in adults may not be as important as is commonly assumed. This is in line with observations suggesting the importance of other non-atopic mechanisms in producing the final common pathway of enhanced bronchial reactivity and reversible airflow obstruction. ${ }^{29} 30$

In this population a number of exposures associated with farming were associated with a decreased risk of atopic asthma while the same exposures were associated with an increased risk of non-atopic asthma. Although this appears paradoxical, these opposite effects may be explained by the potential underlying mechanisms. Briefly, it is well known-particularly from the occupational environment-that microbial exposures such as endotoxin can induce strong neutrophilic airway inflammation and subsequent non-IgE mediated reversible airflow obstruction (that is, non-atopic asthma). ${ }^{28}{ }^{29}$ This therefore explains the positive association between microbial exposure and non-atopic asthma seen in our study. The same microbial agents have also been suggested to inhibit IgE production by inhibiting Th2 driven immune responses, ${ }^{31}$ providing a potential explanation for the observed protective effects of microbial exposure against atopic asthma. Interactions between both suggested pathways are currently unclear, and it is also not clear whether both pathways are activated at the same exposure levels. No effect of exposure on atopy was found in our study; if microbial exposure does indeed exert its protective effect on asthma by inhibiting atopic immune responses, then a protective effect should also be apparent for atopy. It therefore appears that the Th1/Th2 paradigm ${ }^{31}$ cannot fully explain the protective effects observed in our study.

Since we did not include a non-farming control group, we were not able to assess the difference in prevalence for both types of asthma between farmers and the general population. However, the overall prevalence of asthma appeared low compared with previous studies in an adult Norwegian population reported by Bakke et al 6 years earlier. ${ }^{32}$ In their study asthma was defined as "ever treated by a physician or in hospital for asthma", which would be expected to include fewer cases than our definition of physician diagnosed asthma. In spite of this, the prevalence of asthma was higher in the general population among subjects occupationally exposed to dust and/or gas (5.4-6.1\%) than in our farming population $(3.7 \%)$. An atopy prevalence of $7.6 \%$ was found 3 years later in a random sample of the general population based on specific IgE tests against five common respiratory allergens. ${ }^{33}$ The prevalence of atopy in the farmers in our study was based on the Phadiatop RAST test which complicates comparisons with the general population. If specific IgE tests on three of these allergens had been applied in our study, however, the prevalence of atopy would have been $8.9 \%$ which is higher than in the general population (unpublished results). These comparisons suggest that farm exposures might have a protective effect on asthma in adult farmers while there are no such indications for atopy.

Previous studies in children showed a similar inverse association between growing up on a farm and atopic asthma. ${ }^{18}$ Although these studies also showed protective effects with current farm exposures, it has been suggested that these exposures should occur earlier in life (that is, during infancy) to exert their protective effects. In our study it is unlikely that the associations between current exposure and current symptoms can be explained by childhood experiences since it is not very likely that current exposures correlate strongly with childhood exposures. In addition, the observations were made within a farming population in which most subjects probably spent their childhood on a farm. Farm exposures may therefore have similar effects in 
adulthood as during early life. However, one has to be aware that the microbial exposure of adult farmers is probably considerably higher than those encountered in early life.

Exposures to fungal spores, endotoxins, and ammonia were significantly correlated, precluding a firm conclusion on the degree to which specific agents contributed to the observed effects. However, it appeared that fungal spores were most strongly associated with atopic and non-atopic asthma. This finding is difficult to ascribe to better statistical properties of the exposure estimates as the precision of fungal spore exposure is probably similar to that of endotoxin exposure and inferior to ammonia, ${ }^{21}$ and larger differences were found between exposure levels of endotoxin than of fungal spores in farmers in the different production groups.

Fungal spore exposure has previously been found to induce nose and eye irritation as well as cough in farmers. ${ }^{20}$ Fungi are also recognised respiratory allergens ${ }^{34}$ and contain $\beta(1,3)$ glucans, a cell wall component with strong immunomodulating properties. Thus, although a role for endotoxin is likely based on previous studies including animal studies, exposure to fungal spores may also play a part. A protective effect of fungal spores on atopic asthma as suggested by the present study has, however, not been reported previously. The association with exposure to ammonia is most likely due to correlation with the other agents since ammonia is a primary irritant and is quickly absorbed in the upper airways.

In conclusion, livestock farmers in Norway had less atopic asthma and more non-atopic asthma than farmers without livestock whereas the prevalence of atopy was similar. Livestock farmers were exposed to high levels of fungal spores and endotoxin, and these agents (as well as ammonia) were inversely associated with atopic asthma. The same exposures were associated with an increased risk of nonatopic asthma. This study suggests that the possible effects of exposure to endotoxin observed during early life may also occur in adults with high occupational exposures, and that exposure to other agents such as fungal spores may also be involved.

\section{ACKNOWLEDGEMENTS}

The authors thank Pharmacia Diagnostics for supplying the reagents for the Phadebas Phadiatop and specific IgE tests, Nycomed Pharma for performing the RAST analyses in the study of the farming population, Per Sandven for the logistics of serum samples, and Tore Wentzel-Larsen for statistical advice. The survey of the farming population was carried out by Erik Melbostad who died in March 1999.

\section{Authors' affiliations \\ W Eduard, National Institute of Occupational Health, Oslo, Norway \\ J Douwes, D Heederik, Institute for Risk Assessment Sciences, Universiteit Utrecht, The Netherlands \\ J Douwes, Centre for Public Health Research, Massey University, Wellington, New Zealand \\ E Omenaas, Institute of Medicine, University of Bergen, Norway}

\section{REFERENCES}

1 Braun-Fahrländer C, Gassner M, Grize L, et al. Prevalence of hay fever and allergic sensitization in farmers' children and their peers living in the same rural community. Clin Exp Allergy 1999;29:28-34.

2 von Ehrenstein OS, von Mutius, Illi S, et al. Reduced risk of hay fever and asthma among children of farmers Clin Exp Allergy 2000;30:187-93.
3 Riedler J, Eder W, Oberfeld G, et al. Australian children living on a farm have less hay fever, asthma and allergic sensitization. Clin Exp Allergy 2000;30: 194-200.

4 Downs SH, Marks GB, Mitakakis Z, et al. Having lived on a farm and protection against allergic diseases in Australia. Clin Exp Allergy $2001 ; 31: 570-5$.

5 Klintberg B, Berglund N, Lilja G, et al. Fewer allergic respiratory disorders among farmers' children in a closed birth cohort from Sweden. Eur J Respir Dis 2001;17:1151-7.

6 Portengen L, Sigsgaard T, Omland $\varnothing$, et al. Low prevalence of atopy in young Danish farmers and farming students born and raised on a farm. Clin Exp Allergy 2002;32:247-53.

7 von Mutius E. The environmental predictors of allergic disease. J Allergy Clin Immunol 2000;105:9-19.

8 Braun-Fahrländer $\mathrm{C}$, Riedler J, Herz U, et al. Environmental exposure to endotoxins and its relation to asthma in school-age children. N Engl J Med 2002;347:869-77.

9 van Hage Hamsten M, Johansson G, Zetterström O. Predominance of mite allergy over allergy to pollens and animal dander in a farming population. Clin Exp Allergy 1987;17:417-23.

10 Iversen M, Pedersen B. The prevalence of allergy in Danish farmers. Allergy 1990;45:347-53.

11 Vogelzang PFJ, van der Gulden JWJ, Tielen MJM, et al. Health-based selection for asthma but not for chronic bronchitis in pig farmers: an evidence based hypothesis. Eur Respir J 1999;13:187-9.

12 Omland $\varnothing$, Sigsgaard T, Hiort C, et al. Lung status in young Danish rurals: the effect of farming exposure on asthma-like symptoms and lung function. Eur Respir J 1999:13:31-7.

13 Iversen M, Dahl R, Korsgaard J, et al. Respiratory symptoms in Danish farmers: an epidemiological study of risk factors. Thorax 1988;43:872-7.

14 Toren K, Horte LG, Järvholm B. Occupation and smoking adjusted mortality due to asthma in Swedish Men. Br J Ind Med 1991;48:323-6.

15 Toren K. Self-reported rate of occupational asthma in Sweden 1990-92. Occup Environ Med 1996;53:757-61.

16 Fishwick D, Pearce N, D'Souza W, et al. Occupational asthma in New Zealanders: a population-based study. Occup Environ Med 1997;54:301-6.

17 Blainey AD, Topping MD, Ollier S, et al. Respiratory symptoms in arable farm workers: role of storage mites. Thorax 1988;43:697-702.

18 Melbostad E, Eduard W. Chronic bronchitis in farmers. Scand J Work Environ Health 1997;23:271-80.

19 Bakke P, Gulsvik A, Eide GE, et al. Smoking habits and lifetime occupational exposure to gases and dusts, including asbestos and quartz, in a Norwegian community. Scand J Work Environ Health 1990;16:195-202.

20 Eduard W, Douwes J, Mehl R, et al. Short term exposure to airborne microbial agents during farm work: exposure-response relations with eye and respiratory symptoms. Occup Environ Med 2001;58:113-8.

21 Melbostad E, Eduard W. Organic dust related respiratory and eye irritation in Norwegian farmers. Am J Ind Med 2001;39:209-317.

22 Douwes J, Versloot $P$, Hollander A, et al. Influence of various dust sampling and extraction methods on the measurement of endotoxin. Appl Environ Microbiol 1995:61:1763-9.

23 Eduard W, Sandven P, Johansen BV, et al. Identification and quantification of mould spores by scanning electron microscopy (SEM): analysis of filter samples in Norwegian saw mills. Ann Occup Hyg 1988;32(Suppl 1):447-55.

24 Heldal K, Skogstad A, Eduard W. Improvements of the quantification of airborne microorganisms in the farm environment by epiluorescence microscopy. Ann Occup Hyg 1996;40:437-47.

25 Preller L, Kromhout H, Heederik D, et al. Modeling long-term average exposure in occupational exposure-response analysis. Scand J Work Environ Health 1995:21:504-12.

26 Eduard W, Bakke B. Expierences with task-based exposure assessment in studies of farmers and tunnel workers. Nor J Epidemiol 1999;142:43-7.

27 Steenland K, Deddens J, Shuhong Shao MA. Biases in estimating the effect of cumulative exposure in log-linear models when estimated exposure levels are assigned. Scand J Work Environ Health 2000;26:37-43.

28 Douwes J, Pearce N, Heederik D. Does environmental endotoxin exposure prevent asthma? Thorax 2002;57:86-90.

29 Douwes J, Gibson P, Pekkanen J, et al. Non-eosinophilic asthma: importance and possible mechanisms. Thorax 2002;57:643-8.

30 Court CS, Cook DG, Strachan DP. Comparative epidemiology of atopic and non-atopic wheeze and diagnosed asthma in a national sample of English adults. Thorax 2002;57:951-7

31 Martinez FD, Holt PG. Role of microbial burden in aetiology of allergy and asthma. Lancet 1999:354:12-5.

32 Bakke P, Eide GE, Hanoa R. Occupational dust or gas exposure and prevalences of respiratory symptoms and asthma in a general population. Eur Respir J $1991 ; 4: 273-8$

33 Omenaas $\mathrm{E}$, Bakke $\mathrm{P}$, Elsayed $\mathrm{S}$, et al. Total and specific serum IgE levels in adults: relationship to sex, age and environmental factors. Clin Exp Allergy 1994;24:530-9.

34 Al-Doory Y, Domson JF. Mould allergy. Philadelphia: Lea \& Febiger, 1984 